\title{
Study of Polypyrrole-Coated MWCNT Nanocomposites for Ammonia Sensing at Room Temperature
}

\author{
Sanjay G. Bachhav, Dilip R. Patil* \\ Nanomaterial Research Laboratory, R.C. Patel Arts, Commerce \& Science College, Shirpur, India \\ Email: ${ }^{*}$ dr.drpatil@gmail.com
}

Received 14 September 2015; accepted 27 October 2015; published 30 October 2015

Copyright @ 2015 by authors and Scientific Research Publishing Inc.

This work is licensed under the Creative Commons Attribution International License (CC BY). http://creativecommons.org/licenses/by/4.0/

(c) (i) Open Access

\begin{abstract}
The nanocomposite of polypyrrole (PPy) and carboxylated multi-walled carbon nanotubes (MWCNT) was synthesized by in situ chemical oxidative polymerization method using $\mathrm{HCl}$ as a dopant and Ammonium persulphate (APS) as an oxidant. The MWCNTs were carboxylic functionalized and were ultrasonicated to obtain uniform dispersion within the PPy matrix. Surface morphology of nanocomposites was investigated by Field Emission Scanning Electron microscopy (FE-SEM) and revealed that the functionalized MWCNTs were well embedded. X-Ray diffraction (XRD), Fourier Transform Infrared (FT-IR) Spectroscopy, Raman spectroscopy and UV-Vis spectroscopy were used to characterize the synthesized PPy-MWCNT nanocomposite. It was found that in situ polymerized PPy layer matrix was formed on carboxylated MWCNT and there was uniform dispersion of MWCNTs within the PPy matrix with significant interaction between PPy and MWCNTs. The response of the prepared PPy-MWCNT nanocomposite sensors was studied in the form of sensitivity towards Ammonia gas $\left(\mathrm{NH}_{3}\right)$. The synergistic effects of the PPy-coated MWCNTs improve the gas sensing properties. Results showed that the sensitivity increased with $\mathrm{NH}_{3}$ concentration and it was also affected by the MWCNT content in PPy matrix. Furthermore, the sensor in pellet form reported here is robust, cost effective and relatively stable at room temperature.
\end{abstract}

\section{Keywords}

Conducting Polymer, Carbon Nanotubes, In Situ Polymerization, Gas Sensing

\section{Introduction}

Ammonia $\left(\mathrm{NH}_{3}\right)$ is one of the most harmful pollutant gases present in atmosphere produced by human activity "Corresponding author.

How to cite this paper: Bachhav, S.G. and Patil, D.R. (2015) Study of Polypyrrole-Coated MWCNT Nanocomposites for Ammonia Sensing at Room Temperature. Journal of Materials Science and Chemical Engineering, 3, 30-44. 
and industrial practices. Its exposure to human being affects health critically [1]. In addition, the presence of ammonia in exhaled human breath beyond certain extent can be treated as symptom of several diseases concern with liver and kidneys [2]. Hence, the detection of ammonia is a very crucial factor in respect to both environmental as well as medical field.

Nanomaterials have been widely used for the preparation of gas sensors to detect variety of gases due to their high surface area and excellent electrical properties [3]-[5]. The metal oxides based sensors developed for various applications were works efficiently, but suffered from low selectivity, short life time and relatively high operating temperature leading to high power consumption [6]. Hence, to overcome the limitations of metal oxide gas sensors, intensive research has been devoted to the development of room temperature operable gas sensors.

Recent studies proved that MWCNTs as one of the ideal materials for gas sensing at room temperature [7] [8] due to its excellent properties. Although, recent studies predicted that MWCNT is one of the ideal materials for gas sensing at room temperature [7] [8], the gas sensing performance could further improve its utility in commercial sector [9] [10]. Therefore, many efforts have been made to overcome their problems and researchers have recognized that functionalized MWCNTs when used with various conducting polymer matrix leads to improve their sensing performance [11].

Conducting polymers are widely used in sensing material due to its cost effectiveness, high sensitivity, fast response and room temperature operation. Kondawar et al. [12] [13] prepared conducting polymer based composite sensor by different approaches for $\mathrm{NH}_{3}$ sensing. Jang et al. [14] incorporated MWCNTs to prepare thin film composite sensors with two different conducting polymers and reported comparative study for $\mathrm{NH}_{3}$ sensing. Among several conducting polymers, polypyrrole (PPy) has been studied extensively in gas sensor applications due to its excellent electrical properties, easy synthesis, good environmental stability and cost effectiveness [15] [16]. Tiwari et al. [17] developed PPy-rGO thin film composite sensor for $\mathrm{NH}_{3}$ sensing and suggest that incorporation of rGO into PPy had improved the sensitivity and response time. Xiang et al. [18] reported PPy-GN decorated with $\mathrm{TiO}_{2}$ thin film sensor by sol-gel method for $\mathrm{NH}_{3}$ sensing and examined its reproducibility, stability etc. Single-walled Carbon nanotubes (SWCNT) based gas sensors were also studied extensively. Hyeok et al. [19] and Huyen [20] were incorporated SWCNT into PPy matrix by simple in-situ polymerization method and they studied the gas sensing performance of thin film composite due to synergistic effect of PPy and SWCNT. Montoya et al. [21] developed $\mathrm{NH}_{3}$ sensor using PPy-Magnetite nanoparticles and effect of magnetite incorporation into PPy matrix on the stability and electrical properties were studied.

The gas sensors developed so far were in thin/thick film and pellet form irrespective of material used. Thin/ thick film gas sensors required the use of substrate for deposition of sensing material with some particular technique. However, the pellet form of gas sensor does not require any substrate and time consuming deposition technique. Therefore, pelletized gas sensors are cost effective, robust and reasonable sensitivity. Sing et al. [22] designed and fabricated pelletized LPG sensor using iron-antimonate nanostructured material. Barkade et al. [23] developed conducting polymer based composite sensor in pellet form for systematic study of LPG sensing. Venkatesan et al. [24] reported the study of conducting polymer-based nanomaterial pelletized sensor for $\mathrm{NH}_{3}$ sensing. Yun et al. [25] prepared PANI-MWCNT composite by applying simple oxyflurination method to control the morphology and discussed its effect on $\mathrm{NH}_{3}$ sensing of composite pellet sensors.

In the present work, polypyrrole-coated multiwalled carbon nanotube composites were synthesized by simple, cost-effective in situ oxidative polymerization method. The gas sensors were prepared in pellet form, which would be robust, cheap and reasonably sensitive to ammonia vapor sensing. The gas sensitive characteristics of composite for different MWCNT content and over wide range of $\mathrm{NH}_{3}$ vapor concentration were investigated at room temperature. The effect of operating temperature, humidity, long term stability was also studied.

\section{Experimental}

\subsection{Materials}

MWCNT and Triton X-100 were received from sigma Aldrich. The pyrrole monomer used was acquired from Spectrochem (Mumbai). Ammonium persulphate (APS) was used as oxidizing agents acquired from SDFC (Mumbai). All the reagents used were analytical grade.

\subsection{Functionalization of MWCNT}

Surface modification and functionalization of MWCNTs were made by using acid boiling reflux treatment. For 
this, MWCNTs ( $0.5 \mathrm{~g}$ ) were suspended in $\mathrm{H}_{2} \mathrm{SO}_{4}$ and $\mathrm{HNO}_{3}$ in a ratio of $3: 1 \mathrm{v} / \mathrm{v}$ to introduce the carboxylic group on the surface of MWCNTs. The suspension was refluxed with vigorous stirring at $80^{\circ} \mathrm{C}$ for $12 \mathrm{~h}$. After cooling to the room temperature, the mixture was filtered with filter paper. The filtrated solid was then washed thoroughly with distilled water until neutral $\mathrm{pH}$, and then washed with ethanol. The collected product was dried in oven at $60^{\circ} \mathrm{C}$ for $12 \mathrm{~h}$. This product is referred to as functionalized MWCNTs (f-MWCNTs) [26].

\subsection{Synthesis of PPy-MWCNT Nanocomposite}

The PPy-MWCNT nanocomposites were synthesized by in situ chemical oxidative polymerization. In a typical synthesis experiment, the desired amount of f-MWCNT was added to $60 \mathrm{ml}$ distilled water. The certain amount of Triton X-100 was added as a surfactant to this mixture so as to disperse the f-MWCNTs in water. The solution then ultrasonicated over $1 \mathrm{~h}$ to form well dispersed f-MWCNT solution. The $2 \mathrm{ml}$ of pyrrole monomer was added into this MWCNT solution with constant stirring. After addition of pyrrole to MWCNT solution, the mixture was again sonicated for $10 \mathrm{~min}$. The $60 \mathrm{ml}$ of $1 \mathrm{M} \mathrm{HCl}$ was prepared and added to the PPy-MWCNT solution. The 0.55 M APS solution was prepared by dissolving required amount of APS into $60 \mathrm{ml}$ distilled water and was added drop wise to Pyrrole-MWCNT-HCl mixture solution for $30 \mathrm{~min}$ with constant stirring. The stirring was continued for $12 \mathrm{~h}$ and then kept standing for $4 \mathrm{~h}$ to obtain polymerized black precipitate. The polymerized solution was then filtered and washed several times with distilled water until the filtrate became acid free, and then washed with acetone, ethanol and methanol. The precipitate was dried in an oven at $60^{\circ} \mathrm{C}$ for $12 \mathrm{~h}$ to obtain PPy-MWCNT nanocomposite.

The six PPy-MWCNT nanocomposite samples were prepared for different amount of f-MWCNTs such as 5 mg, $10 \mathrm{mg}, 20 \mathrm{mg}, 40 \mathrm{mg}, 80 \mathrm{mg}$ and $160 \mathrm{mg}$ keeping PPy concentration constant. The \% content of f-MWCNT in PPy matrix was $0.25 \%, 0.50 \%, 1 \%, 2 \%, 4 \%$ and $8 \%$. The pristine PPy sample was also synthesized using the similar method given above except use of MWCNT.

\subsection{Characterization}

The morphology of the synthesized nanocomposites was studied on Hitachi S4800 Type-II Field Emission Scanning Electron Microscope. X-ray diffraction (XRD) patterns were performed on a Bruker D8 Advance diffractometer with $\mathrm{Cu} \mathrm{K} \alpha$ radiation. Raman spectra were recorded at room temperature on JY Horiba HR800 Raman spectrometer employing a $488 \mathrm{~nm}$ Argon laser beam. Fourier transform infrared (FT-IR) spectra were recorded on a Shimadzu IR Affinity spectrophotometer with $\mathrm{KBr}$ pellets to ensure functional groups. UV-Vis spectra were recorded on Shimadzu UV-2450 spectrophotometer using quartz cell and $N, N$-dimethylformide (DMF) as a solvent.

\subsection{Gas Sensor Fabrication and Testing Method}

The pure PPy and PPy-MWCNT nanocomposites powder was pressed into pellet of diameter $15 \mathrm{~mm}$ and thickness $\sim 6 \mathrm{~mm}$ by hydraulic press (Kimaya, Pune). The compressed pressure and time was optimized to maintain porosity as high as possible. The electrical contacts are made at a distance about $12 \mathrm{~mm}$ with the help of silver paste on the surface of the pellet to form gas sensing element.

The sensor testing was carried out in an indigenous designed instrument and fabricated by Subhadra Scientific, Pune. The setup of gas sensing apparatus is shown in Figure 1. The sensing pellet was kept in sample holder, which then placed inside the glass chamber $(0.5 \mathrm{~L})$ with gas inlet and outlet ports. Each sample was kept inside the glass chamber at atmospheric pressure for at least $30 \mathrm{~min}$ before injecting the gas to stabilize the resistance of the sample. The electrical resistance was measured by a Multimeter (Keithley, 2000), that was connected to computer for data acquisition. The performance of the sensor was measured in terms of $\%$ sensitivity (S), which is defined as:

$$
S(\%)=\left(\frac{R_{g}-R_{a}}{R_{a}}\right) \times 100
$$

where, $R_{a}$ and $R_{g}$ are values of sensor resistance in air and in presence of $\mathrm{NH}_{3}$ gas, respectively.

\section{Results and Discussion}

\subsection{Characterization of PPy-MWCNT Nanocomposite}

The Field Emission Scanning Electron Microscopy (FE-SEM) images of f-MWCNT, pure PPy, and PPy-MWCNT 
nanocomposites are shown in Figure 2. It can be observed that many nanotubes are loosely entangled together without any particle-like impurities as shown Figure 2(a). The pure PPy has spherical granular structure with particle size in the range $100-400 \mathrm{~nm}$ [27] as observed in Figure 2(b). The PPy was coated onto surface of MWCNT retaining its spherical granular structure for $4 \mathrm{wt} \%$ MWCNT content sample as presented in Figure 2(c). Such granular morphology is appropriate for gas sensing application. The PPy is uniformly coated onto the MWCNT surface for higher content of MWCNT (8 wt\%) as observed in Figure 2(d). The diameter of PPyMWCNT ( $8 \mathrm{wt} \%$ MWCNT) increased to about $80 \mathrm{~nm}$ as compared to $10 \mathrm{~nm}$ diameter of pristine f-MWCNT. The micrograph images of composites clearly reveal that every individual MWCNT were coated by PPy and evenly well dispersed within PPy matrix.

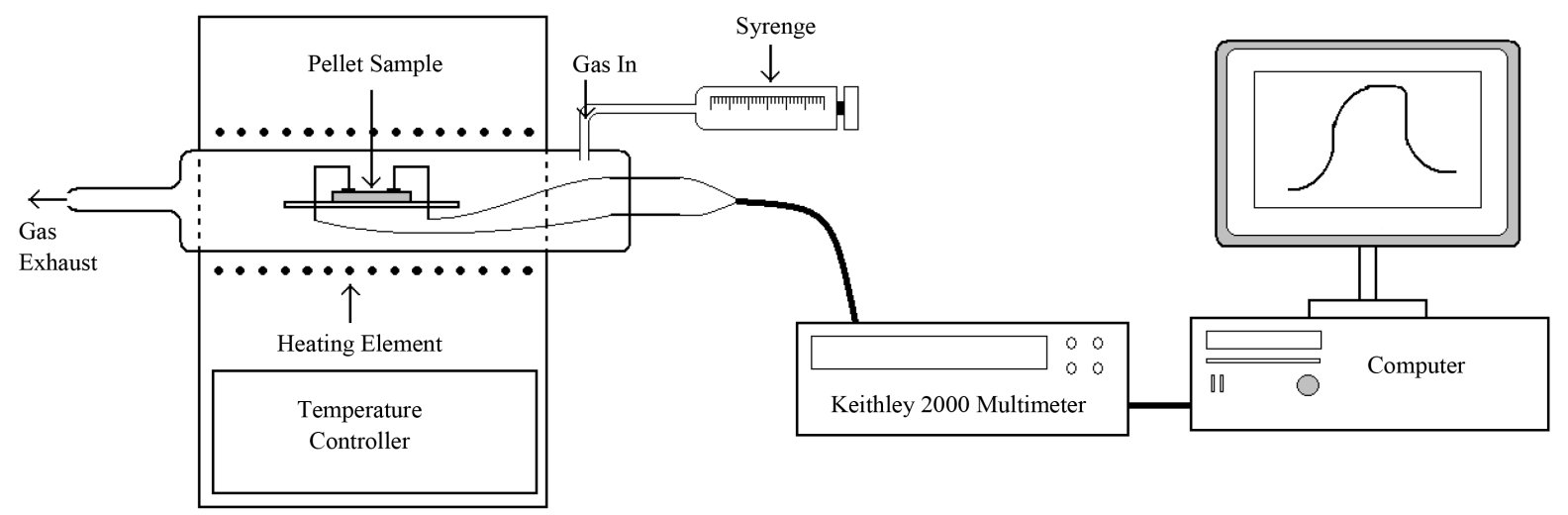

Figure 1. Schematic illustration of gas sensing experimental setup.

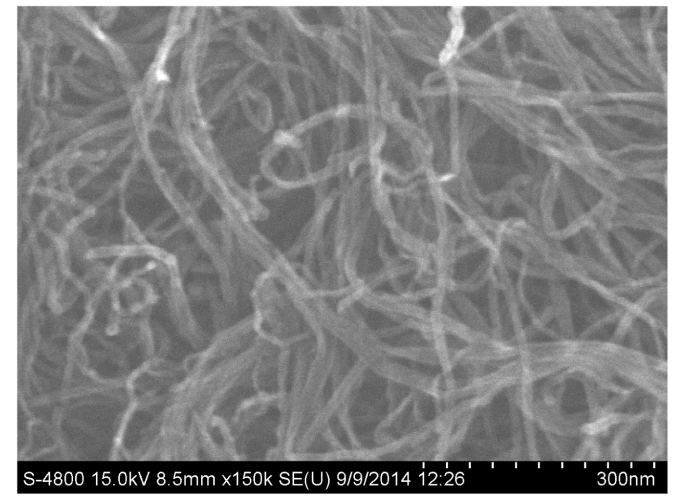

(a)

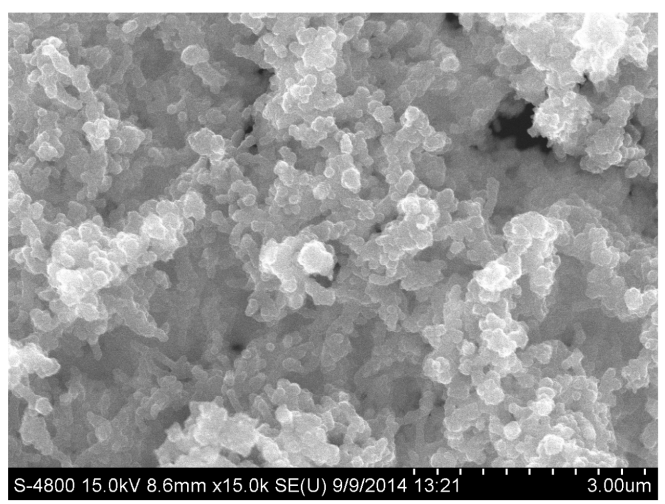

(c)

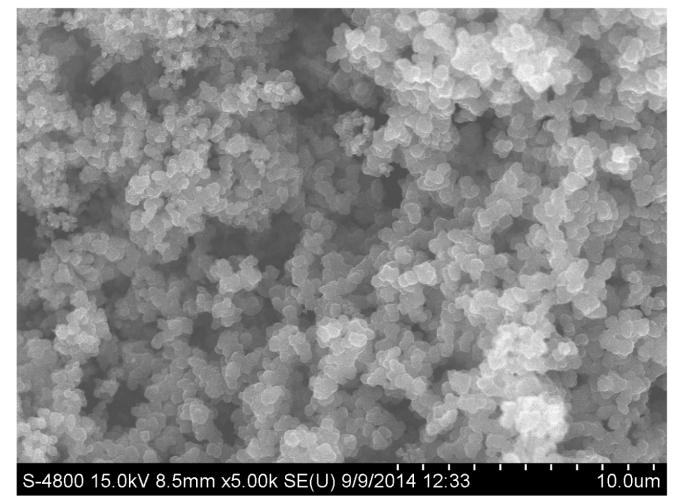

(b)

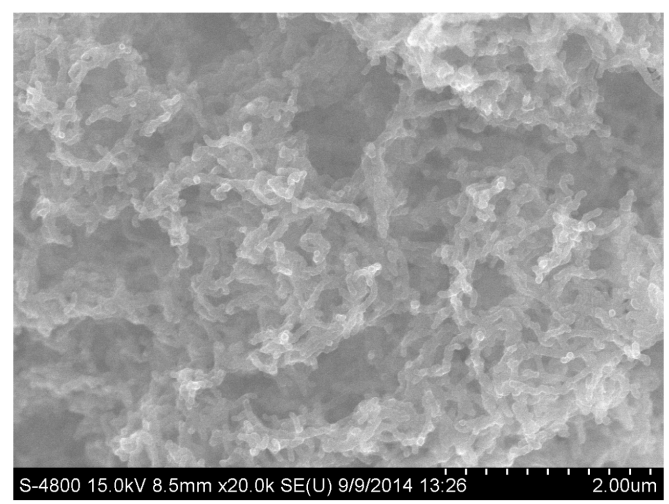

(d)

Figure 2. FE-SEM images of (a) f-MWCNT (b) pure PPy and PPy-MWCNT nanocomposites at (c) 4 wt\% and (d) 8 wt\% MWCNT content. 
The XRD pattern of PPy, PPy-MWCNT nanocomposites and f-MWCNT are shown in Figure 3. The results are quite in agreements with the results reported by Zhang et al. [28]. The spectra show the peak at $2 \theta=24.4^{\circ}$ and $43^{\circ}$ can be attributed to graphite like structure. The existence of weak and broad diffraction peak at $2 \theta=15^{\circ}$ $33^{\circ}$ for pure PPy indicates that the PPy is amorphous in nature. For PPy-MWCNT nanocomposite, one broad and high intense peak appeared at around $2 \theta=25^{\circ}$ and small intense peak appeared at $2 \theta=43^{\circ}$, which is the characteristic peak of PPy and graphite like structure of MWCNT respectively. The overlapped diffraction peaks of MWCNT with PPy depict the formation of PPy-MWCNT nanocomposite by in situ polymerization synthesis process [29].

The Raman spectra of Pure PPy, MWCNT and PPy-MWCNT nanocomposites are shown in Figure 4. In the

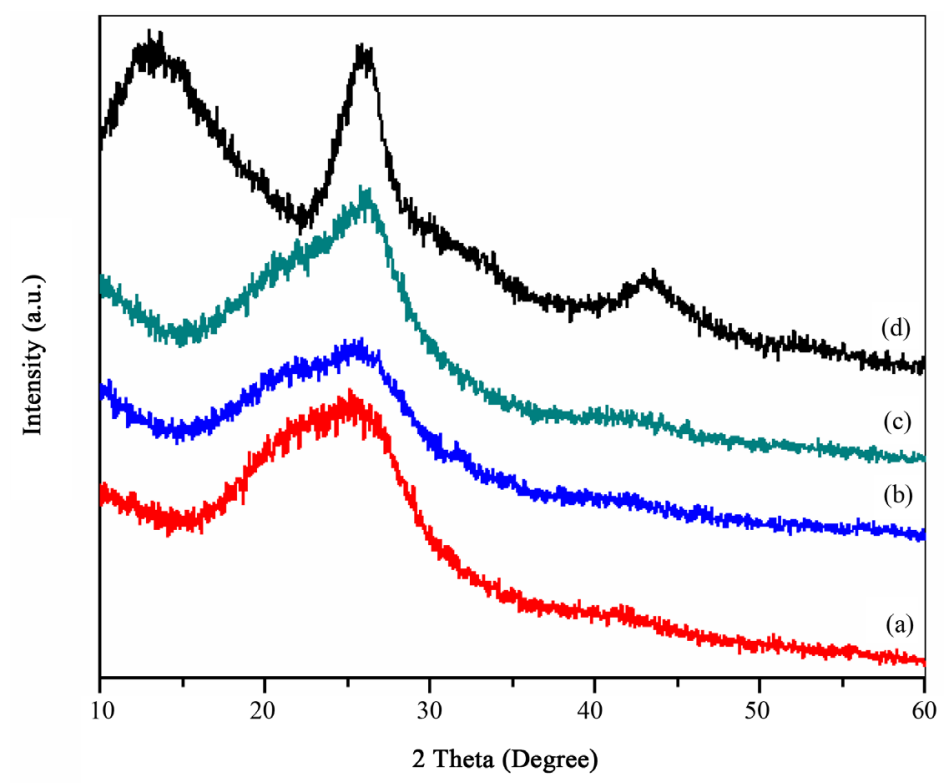

Figure 3. XRD patterns of (a) pure PPy, PPy-MWCNT nanocomposites at (b) $4 \mathrm{wt} \%$, (c) $8 \mathrm{wt} \%$ MWCNT content and (d) f-MWCNT.

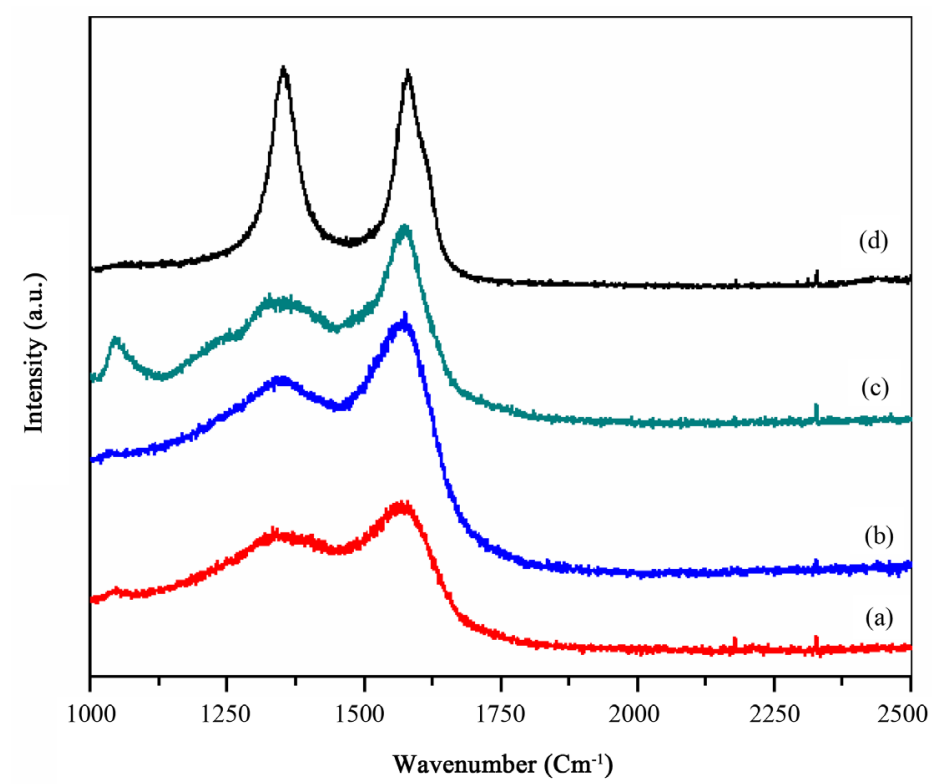

Figure 4. Raman spectroscopy of (a) pure PPy, PPy-MWCNT nanocomposites at MWCNTs contents of (b) 4 wt \% (c) 8 wt $\%$ and (d) f-MWCNT. 
Raman spectrum of pure PPy, the characteristics bands appears at 1572 and $1337 \mathrm{~cm}^{-1}$, which were assigned to the $\mathrm{C}=\mathrm{C}$ backbone stretching and the ring stretching vibration of PPy respectively [30]. The Raman spectrum of the carboxylated MWCNTs showed two prominent characteristics peaks-D band $\left(1368 \mathrm{~cm}^{-1}\right)$ and G band (1590 $\mathrm{cm}^{-1}$ ). In the Raman spectrum of PPy-MWCNT nanocomposite, the D band becomes broad during the synthesis process. The G-band of the MWCNTs and the $\mathrm{C}=\mathrm{C}$ stretching vibrations are merged into a broad band with a maximum at $1579 \mathrm{~cm}^{-1}$ [31]. In addition, both these D and G band shift slightly, when MWCNT was introduced into the PPy matrix. This is probably due to the doping of carboxyl group of functionalized MWCNTs to PPy backbone and $\pi-\pi$ interaction between PPy and MWCNTs [29].

The FT-IR spectra recorded for PPy, f-MWCNT and PPY-MWCNT nanocomposites are shown in Figure 5. In the FT-IR spectrum of MWCNT, the small intense peak 1683 and $1729 \mathrm{~cm}^{-1}$ corresponds to the C=C stretching mode and $\mathrm{C}=\mathrm{O}$ stretching vibrations of the- $\mathrm{COOH}$ group, respectively, indicated that the MWCNTs had been successfully oxidized into carboxylated carbon nanotubes [29] [32]. In the spectra of Pure PPy, the absorption bands obtained at $1558 \mathrm{~cm}^{-1}$ and $1464 \mathrm{~cm}^{-1}$ corresponds to the anti-symmetric and symmetric C-C stretching vibration respectively in pyrrole ring. The band at $1291 \mathrm{~cm}^{-1}$ is related to the $\mathrm{C}-\mathrm{N}$ in-plane, and the bands at 1175 and $1042 \mathrm{~cm}^{-1}$ are associated to the $\mathrm{C}-\mathrm{H}$ bending modes while the band for $\mathrm{C}-\mathrm{H}$ out-of-plane deformation vibration was observed at $898 \mathrm{~cm}^{-1}$ [29]. The peaks at $672 \mathrm{~cm}^{-1}$ corresponding to ring deformation, 948 $\mathrm{cm}^{-1}$ corresponding to C-H deformation [33]. It was observed that all the spectra contain a very weak but broad adsorption band in the region between $2500 \mathrm{~cm}^{-1}$ to $3500 \mathrm{~cm}^{-1}$, which is commonly assigned for the adsorption band of O-H, C-H, N-H groups [20]. The characteristic peaks of PPy at $1454 \mathrm{~cm}^{-1}$ and $1545 \mathrm{~cm}^{-1}$ are also observed for the PPy-MWCNT composites, indicating the formation of PPy in presence of MWCNT. It is important to observed that peak of PPy at $1545 \mathrm{~cm}^{-1}$ becomes slightly broaden in almost all nanocomposite samples and the characteristic peaks of MWNTs are hardly seen which indicates the better interaction between the aromatic ring of pyrrole and MWCNT [34] [35]. It is observed that all the peaks appeared in the fingerprint region of PPy are observed in the FT-IR spectra of PPy-MWCNT nanocomposites indicating that main constituents of PPy and its nanocomposite with MWCNTs have the same chemical structure. However, the incorporation of MWCNT results into the slight shifting of FT-IR bands from its original position. This shift in peak position is due to the strong synergetic interaction, loss in conjugation and molecular order after modification of PPy with MWCNTs and can be attributed to chemical interactions between active sites in PPy and MWCNTs [36].

To understand the effect of addition of MWCNTs in PPy matrix, the UV-vis spectroscopy was carried out. Figure 6 depicts the UV-vis spectra of PPy, PPy-MWCNT nanocomposites and MWCNT. As shown in curve (a) of Figure 6, PPy sample shows broad absorption peak at $475 \mathrm{~nm}$ which is in good agreement with reported [36].

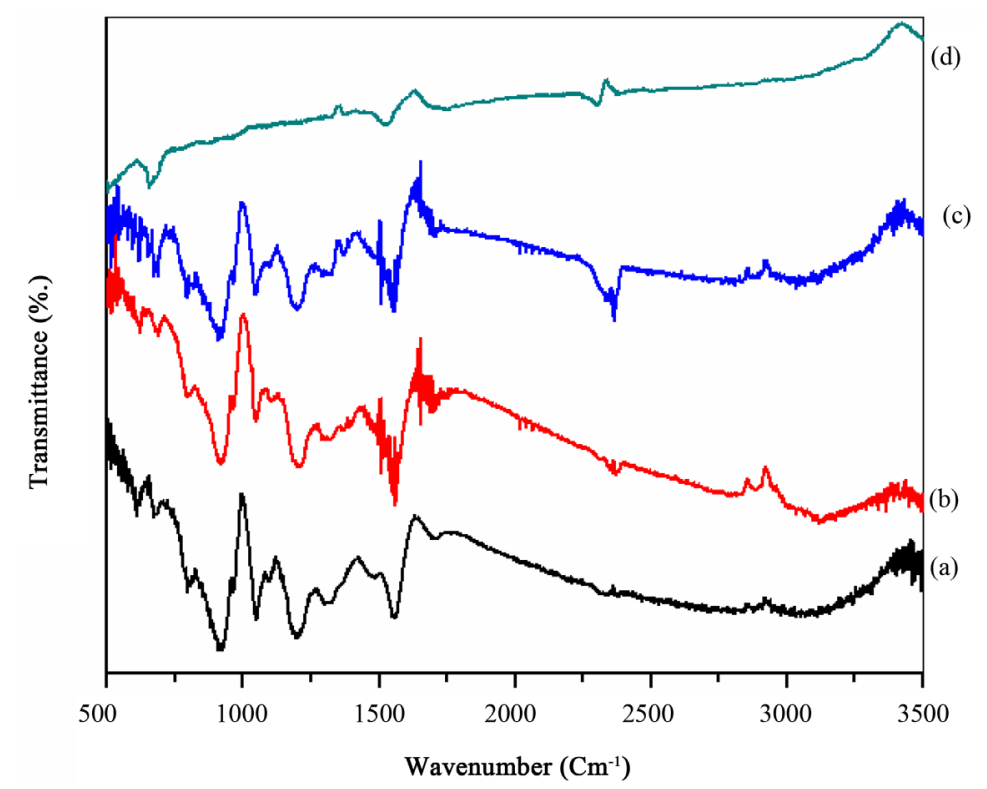

Figure 5. FT-IR spectrum of (a) pure PPy, PPy-MWCNT nanocomposites at MWCNT content of (b) 4 wt\%; (c) 8 wt\%; and (d) f-MWCNT. 


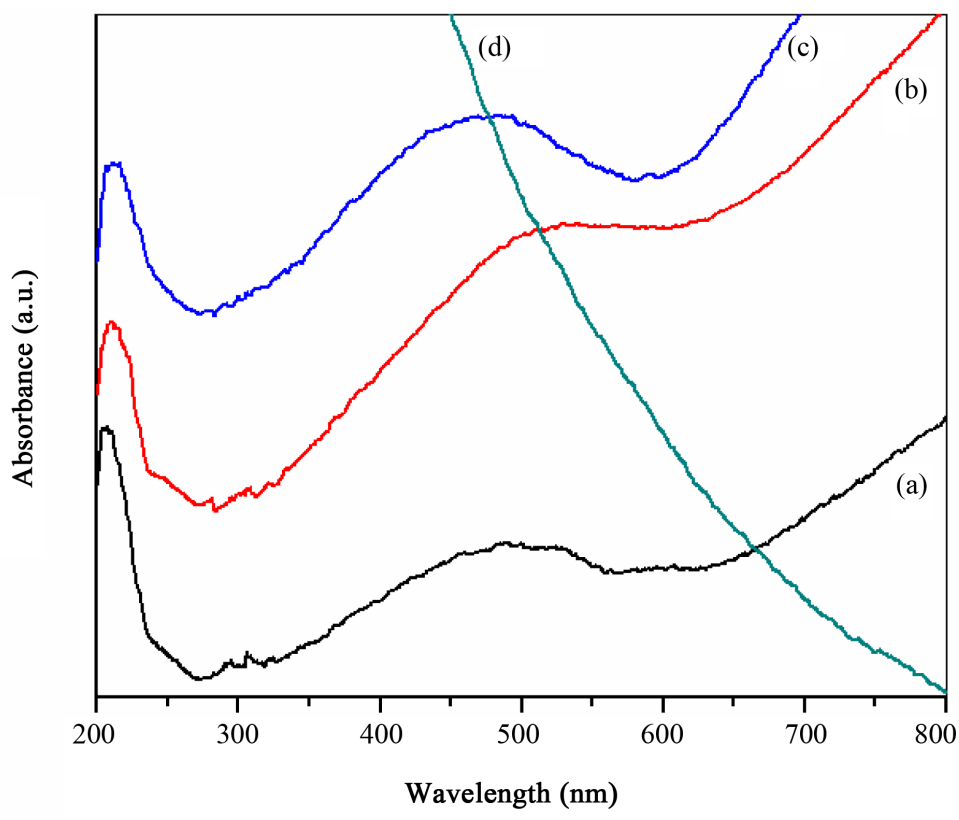

Figure 6. UV-Visible spectra of (a) pure PPy, PPy-MWCNT nanocomposites at (b) $4 \mathrm{wt} \%$, (c) $8 \mathrm{wt} \%$ MWCNTs contents and (d) f-MWCNT.

There is no absorption in the $300-800 \mathrm{~nm}$ range for MWCNT sample as reported by T.-M. Wu et al. [37]. The typical absorption peak of PPy-MWCNT composite at approximately $490 \mathrm{~nm}$ is attributed to the transition from the valence band to the anti-bonding polaron state [38], showing that the synthesized PPy-MWCNT composite are in the doped state. The amount of MWCNTs dispersed can be determined from the absorbance occurred in the visible range. The shift in absorption peak in PPy-MWCNTs nanocomposite towards higher wavelength indicates that there is strong interaction between PPy and MWCNTs and poor conjugation which changes PPy from quinoid structure with large conjugation to benzoid structure with almost no conjugation.

\subsection{I-V Characteristics}

I-V curves of PPy-MWCNT (4 wt\% and 8 wt\%) composites along with pure PPy at room temperature represented in Figure 7. All the sensors exhibited ohmic behavior within the range $-4 \mathrm{~V}$ to $+4 \mathrm{~V}$. This ohmic behavior clearly indicates that the change in resistance could be only due to the influence of the gas exposure.

\subsection{Sensing Mechanism and Gas Sensing Test}

\subsubsection{Sensing Mechanism}

The electrical resistance of PPy-MWCNT sensor increased when it exposed to $\mathrm{NH}_{3}$ gas. The change in electrical resistance of sensor is attributed to the charge transfer mechanism between $\mathrm{NH}_{3}$ and PPy-MWCNT surface. Such p-type behavior was also observed in PPy-based and MWCNT-based sensors [39]-[42], where PPy and MWCNT behave as p-type semiconductors. This suggest that, the adsorption of $\mathrm{NH}_{3}$ on PPy-MWCNT composite reduces the number of holes in PPy and MWCNT leads to increase in resistance, as $\mathrm{NH}_{3}$ is an electronic donating gas. However the amount of change in resistance depends on the interaction between PPy and MWCNT. In other words, the sensitivity determining aspect of the composite was related to its morphology. As it is observed that the MWCNTs were well embedded within the PPy, thereby increasing its surface area to the $\mathrm{NH}_{3}$ thus giving higher sensitivity.

\subsubsection{Effect of MWCNT Content}

The sensing characteristics of all prepared nanocomposite sensors including pristine-PPy for $2000 \mathrm{ppm} \mathrm{NH}_{3}$ concentration at room temperature is shown in Figure 8. It can be observed that the response of composite to $\mathrm{NH}_{3}$ gas increased initially as MWCNT content increased up to $4 \mathrm{wt} \%$, and decreased afterward for further 


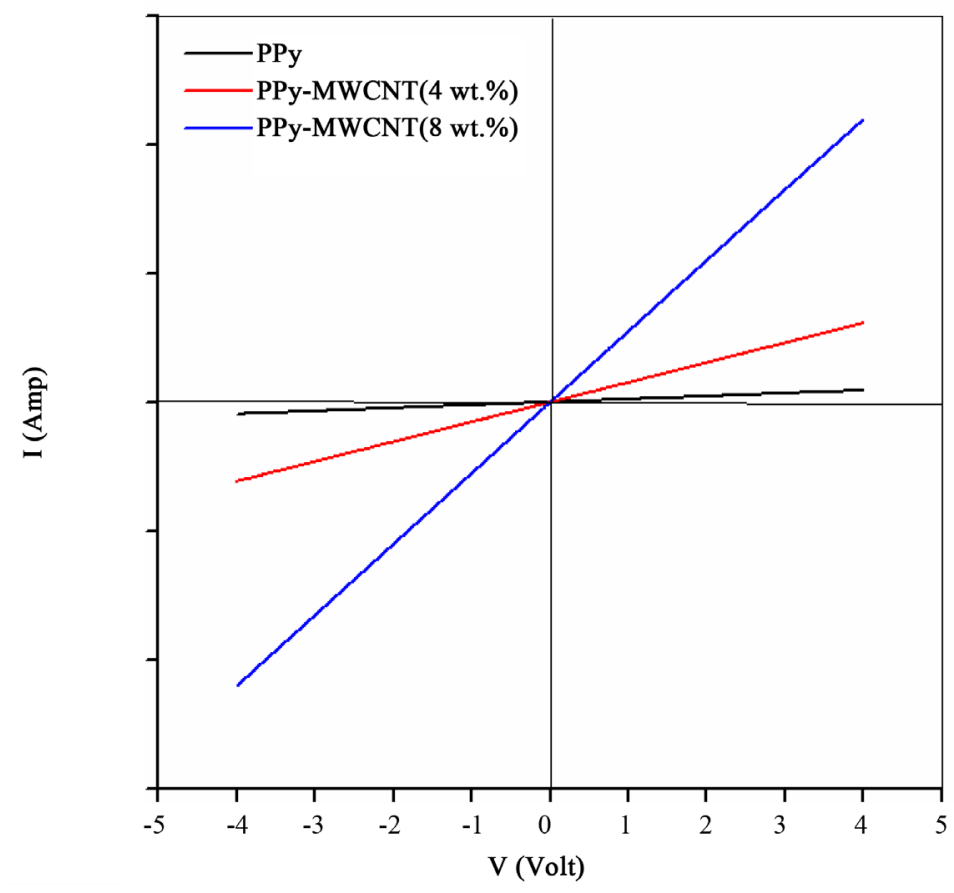

Figure 7. I-V characteristics of PPy and PPy-MWCNT nanocomposites.

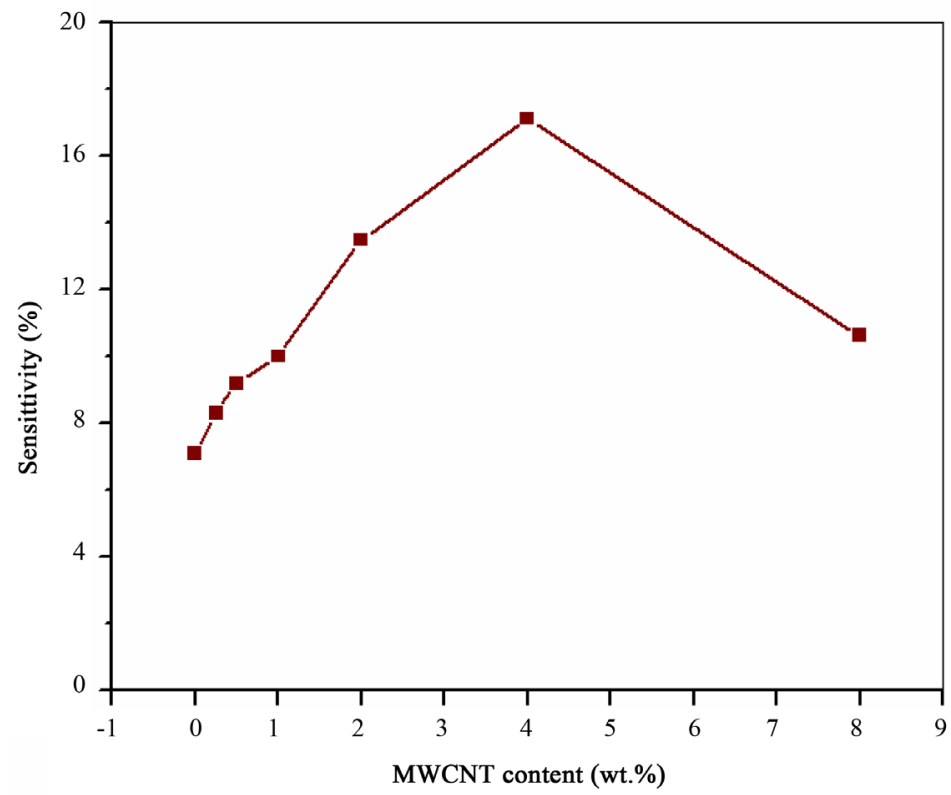

Figure 8. Response of PPy-MWCNT composite sensors as a function of MWCNT content.

increase in MWCNT. The PPy-MWCNT sensor synthesized for $4 \mathrm{wt} \%$ MWCNT show the highest response (17.11\%) at room temperature. Therefore it is predicted that the sensitivity of composite sensor is greatly influenced by variation in the MWCNT content. This is because the content of CNT strongly affects the morphology and the electrical property of the PPy-MWCNT composites [43]-[45]. The increase in sensitivity with increase in MWCNT content is attributed to increase of surface area of composite material, providing more active sites for adsorption of $\mathrm{NH}_{3}$ gas molecules and thus increase in sensitivity is obvious. However further increase in MWCNT content makes the composite electrically shorted, thereby increasing the percolation effect by highly 
conductive carbon nanotubes [27]. Also, the conductivity of the composite is dominated by the metallic CNTs. This suggests that both these phenomenon could be responsible for decrease in the composite sensor response.

\subsubsection{Effect of $\mathrm{NH}_{3}$ Concentration}

The variation of sensor response of PPy-MWCNT (4 wt\%) sample at room temperature with $\mathrm{NH}_{3}$ concentration is indicated in Figure 9. The graph revealed that the sensitivity of PPy-MWCNT composite sensor linearly increased. It was found that PPy-MWCNT composite exhibits higher response than pure PPy. The higher sensitivity of PPy-MWCNT composite is due to the synergistic effect of pure PPy and due to carboxylic functionalized MWCNTs. The sensitivity of composite sensor increased from 3.07\% to $17.11 \%$ over 200 - 2000 ppm concentration range of $\mathrm{NH}_{3}$. This is because the sensitivity of sensor depends on the removal of adsorbed oxygen molecules by reaction of target gas and generation of electrons. For a smaller concentration of gas exposed on fixed surface area of sensor, lower surface reaction was occurred due to lower coverage of gas. An increase in gas concentration raises the surface reaction due to larger surface coverage [46]. Chen et al. [45] study on PPyMWCNT thin film prepared by different oxidizing agent and dopant showed the sensitivity in the range $17-23$ at $2000 \mathrm{NH}_{3}$. In our study, the observed sensitivity of $17.11 \%$ at $2000 \mathrm{ppm}$ was lies in this range.

\subsubsection{Gas Response Curve}

The transient gas response curves of the sensor to $2000 \mathrm{ppm}$ of $\mathrm{NH}_{3}$ at room temperature and $55^{\circ} \mathrm{C}$ temperature are shown in Figure 10. A sharp rise in resistance (consequently \% sensitivity) was observed at both temperatures, as adsorption process proceeds very fast at initial stage and subsequently, it become slower near the equilibrium. This may attribute to the fact that there are a great way of accessible vacant surface sites are available for adsorption during the initial stage, thereafter the remaining vacant surface sites becomes less with time [47]. It was observed that sensor showed extremely slow recovery after removal of $\mathrm{NH}_{3}$ gas at room temperature and it takes several min to recover completely as reported by other researchers [48]. At $55^{\circ} \mathrm{C}$ temperature, the resistance (consequently \% sensitivity) found to be decreased with decrease in recovery time took place from several min to $34 \mathrm{sec}$. Therefore increase in temperature causes improvement in recovery time. This is attributed to that the desorption rate of $\mathrm{NH}_{3}$ molecule may increased due to rise in temperature [35]. The observed response time of composite sensor to $\mathrm{NH}_{3}$ gas was $34 \mathrm{sec}$ and $32 \mathrm{sec}$. at room temperature and at $55^{\circ} \mathrm{C}$ respectively.

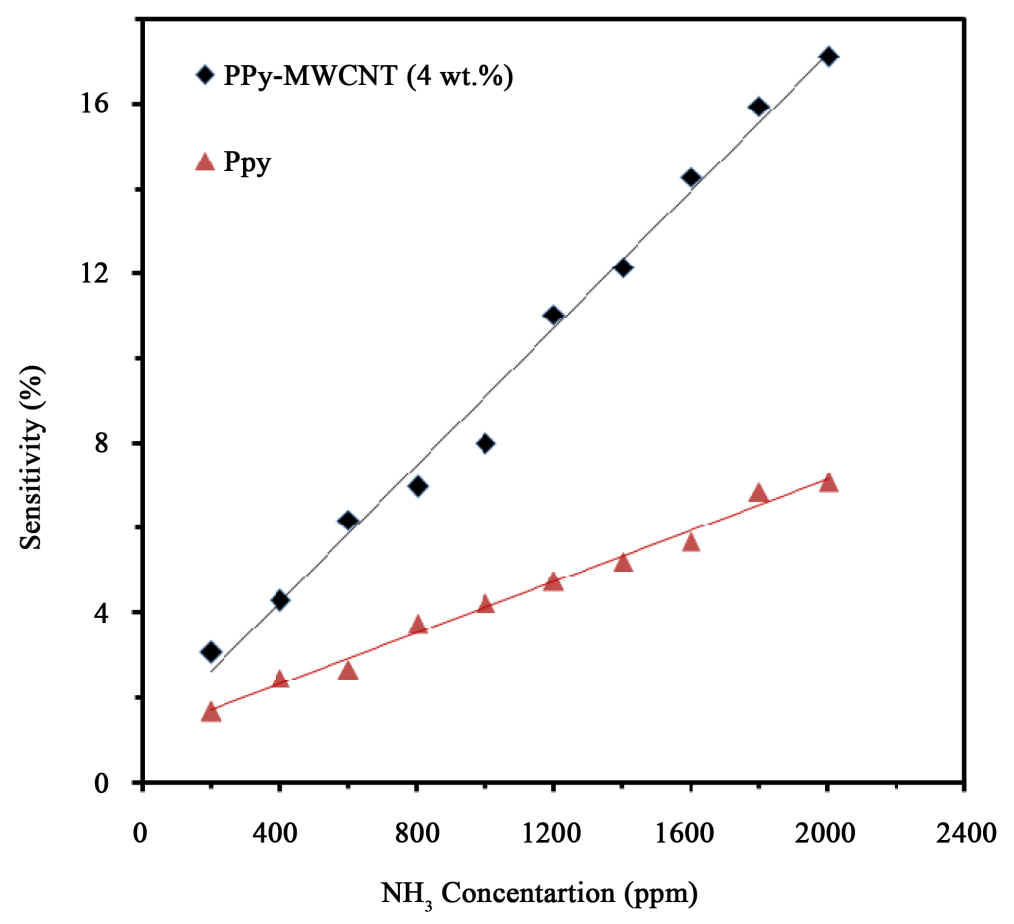

Figure 9. Response of PPy and PPy-MWCNT (4 wt\%) sensors as a function of $\mathrm{NH}_{3}$ concentration. 


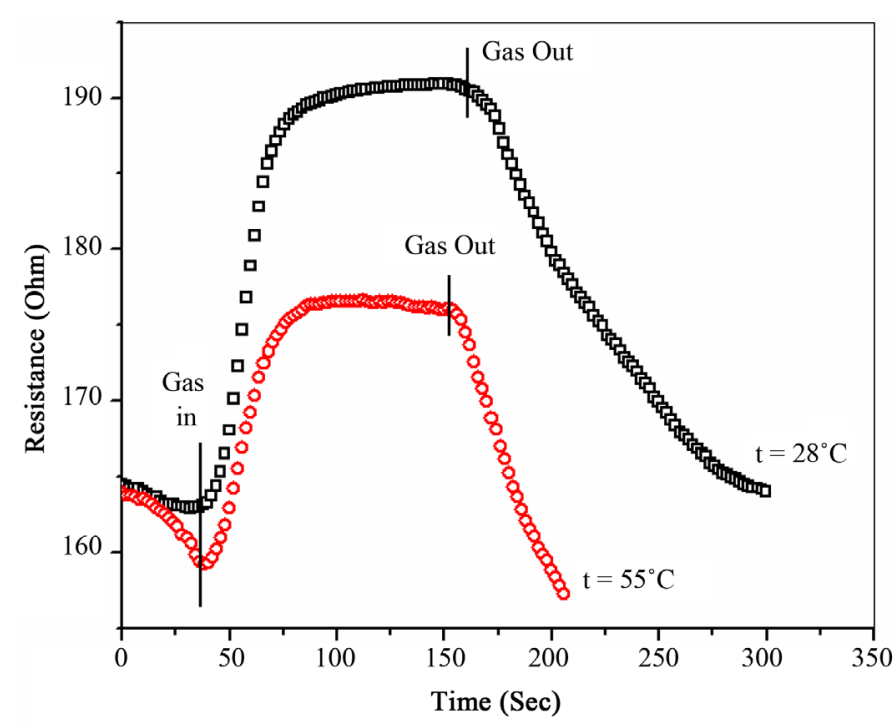

Figure 10. Response-recovery of PPy-MWCNT (4 wt\%) sensor towards $2000 \mathrm{ppm} \mathrm{NH}_{3}$.

\subsubsection{Effect of Operating Temperature}

The purpose of the present work was to develop room temperature $\mathrm{NH}_{3}$ sensor. However, we also tested the composite sensor at different temperatures to study the effect of operating temperature. The obtained response for PPy-MWCNT (4 wt\%) sensor at operating temperatures such as $28^{\circ} \mathrm{C}, 45^{\circ} \mathrm{C}, 55^{\circ} \mathrm{C}$ and $65^{\circ} \mathrm{C}$ at $2000 \mathrm{ppm}$ of $\mathrm{NH}_{3}$ concentration represented in Figure 11. The response of sensor found to be decrease with increase in operating temperature. The reason behind explained as follow. The gas sensing process involves diffusion of gas molecules in the bulk of sensor and, the reaction between them. Temperature can affect both the process; consequently, an increase in temperature will shift the equilibrium to desorption, as adsorption always prefer low temperature [35]. Therefore gas sensing response of composite will decrease with increase in temperature.

\subsubsection{Effect of Humidity}

To study the effect of humidity on $\mathrm{NH}_{3}$ sensing performance of composite sensor, the salt solution method described elsewhere [49] was used. The saturated salt solutions of $\mathrm{NH}_{4} \mathrm{NO}_{3}, \mathrm{NaCl}, \mathrm{KCl}$ and $\mathrm{KNO}_{3}$ were used to obtain $62 \%, 75 \%, 84 \%$ and $92 \%$ humidity levels respectively. Figure 12 indicates the variation in sensitivity of PPy-MWCNT (4\%) sample with humidity exposed to $2000 \mathrm{ppm}$ of $\mathrm{NH}_{3}$ gas. A little fall in sensitivity ( 9\%) observed in 35\% - 62\% range of relative humidity but decreased significantly thereafter. It is known that PPy is generally stable at very low temperature and low humidity, but affect at high humidity [50]. Furthermore, the resistance of carboxylic functionalized MWCNT increased with increase in humidity due to their hydrophilic nature [51]. Therefore it is expect that PPy-MWCNT can also be stable to some extent at lower humidity but heavily affected at high humid environment.

\subsubsection{Stability}

When evaluating reliability of sensor, stability is the vital factor to be considered. The sensitivity of PPyMWCNT sensor to $2000 \mathrm{ppm}$ of $\mathrm{NH}_{3}$ gas was recorded at room temperature for 40 days periodically at an interval of 4 days and is represented in Figure 13. It can observe form the response curve that the sensitivity dropped by only $\sim 5 \%$ after 40 days. This might be due to that the polymer based sensor posses a common drawback of decrease in response due to aging-induced effects [52].

\subsubsection{Selectivity}

The selectivity of PPy-MWCNT composite sensor was also tested for other gases such as Liquid petroleum gas (LPG), Ethanol, Methanol, Acetone and Chloroform at the same concentration and the response is represented in Figure 14. The PPy-MWCNT sensor was found to be highly selective towards $\mathrm{NH}_{3}$ among the other gases. 


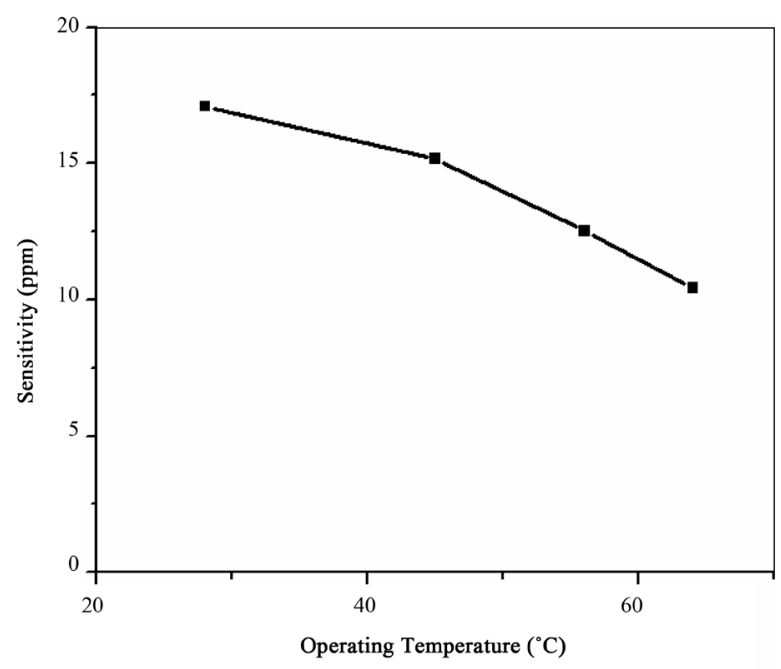

Figure 11. Response of PPy-MWCNT (4 wt\%) sensor with variation in operating temperature.

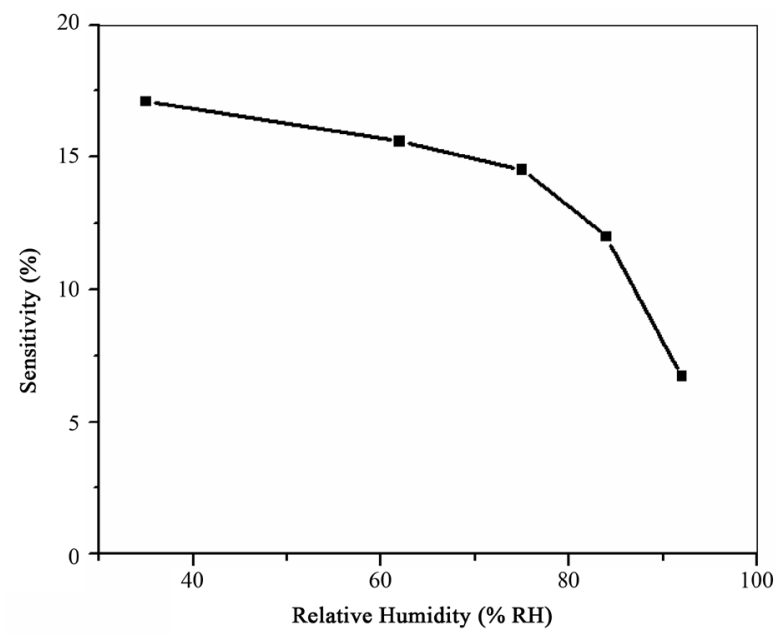

Figure 12. Response of PPy-MWCNT (4 wt\%) sensor with variation in relative humidity.

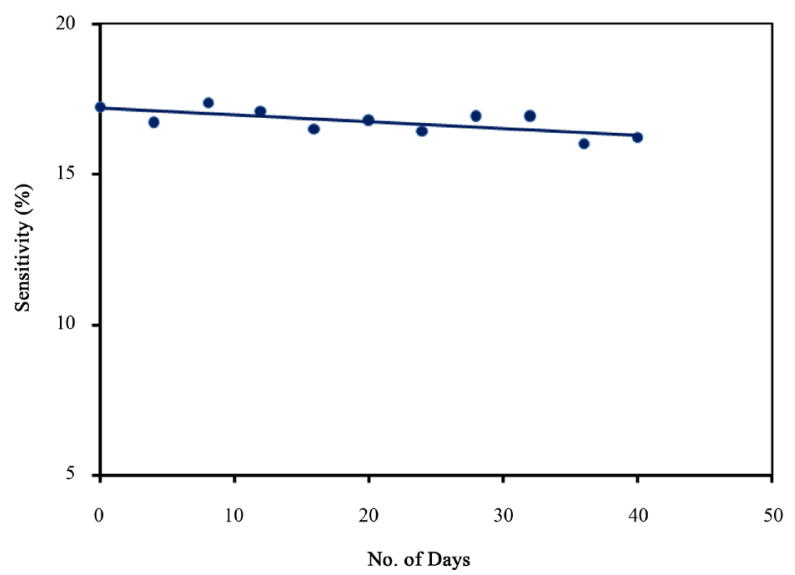

Figure 13. Gas sensing stability of PPy-MWCNT (4 wt\%) sensor towards $2000 \mathrm{ppm} \mathrm{NH}_{3}$. 


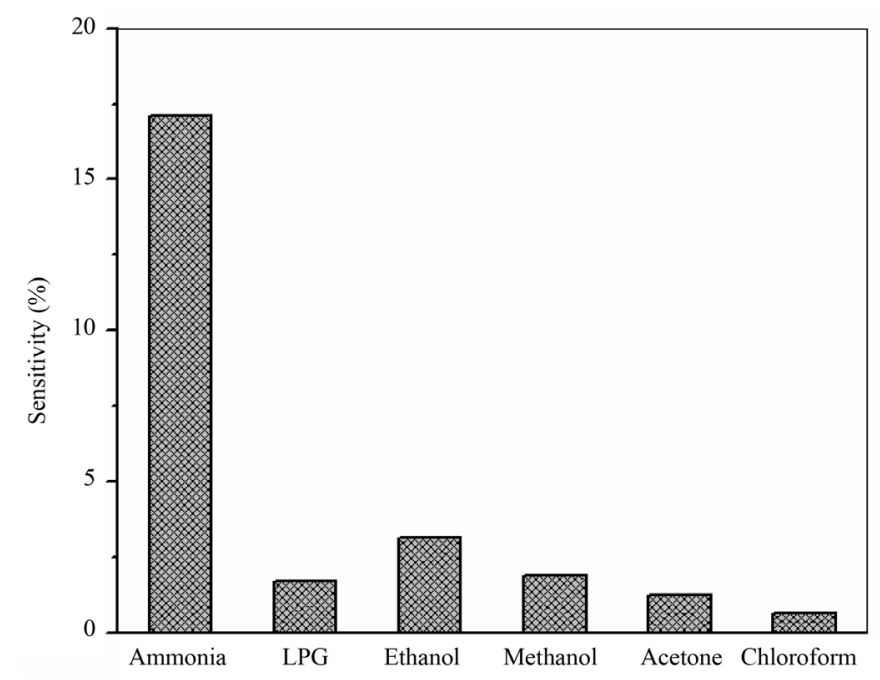

Figure 14. Gas sensing selectivity of PPy-MWCNT (4 wt\%) sensor towards $2000 \mathrm{ppm} \mathrm{NH}$.

\section{Conclusion}

A Polypyrrole-multiwalled carbon nanotube (PPy-MWCNT) composite for different MWCNT content has been successfully synthesized by in situ chemical oxidative polymerization. FE-SEM images confirm that PPy has successfully formed on the surface of MWCNTs. XRD, Raman, and FT-IR spectrum revealed the incorporation of MWCNT into the PPy matrix. UV-vis spectrum shows that the synthesized PPy-MWCNT composites are in the doped state. The PPy-MWCNT nanocomposites pellet sensors showed good sensitivity to $\mathrm{NH}_{3}$ gas at room temperature. The content of MWCNT in the PPy significantly affects the sensitivity towards $\mathrm{NH}_{3}$. The most sensitive PPy-MWCNT nanocomposites sensor to $\mathrm{NH}_{3}$ gas obtained with $4 \mathrm{wt} \%$ MWCNT content and found to be stable in operation against the variation in operating temperature and humidity.

\section{Acknowledgements}

The authors are grateful to University Grant Commission, New Delhi for financial support through minor research project scheme No. F. 47-809/13 (WRO). The authors are also thankful to "UGC-DAE Consortium for Scientific Research centre, Indore" for providing the characterization facilities and the management of R.C. Patel Educational trust for their continuous encouragement and support.

\section{References}

[1] Timmer, B., Olthuis, W. and Van Den Berg, A. (2005) Ammonia Sensors and Their Applications-A Review. Sensors and Actuators B: Chemical, 107, 666-677. http://dx.doi.org/10.1016/j.snb.2004.11.054

[2] Risby, T.H. and Solga, S. (2006) Current Status of Clinical Breath Analysis. Applied Physics B, 85, 421-426. http://dx.doi.org/10.1007/s00340-006-2280-4

[3] Kalyamwar, V. and Raghuwanshi, F. (2013) $\mathrm{TiO}_{2}$ Modified ZnO Thick Film Resistors as Ammonia Gas Sensors. Advanced Materials Letters, 4, 895-898.

[4] Ansari, M.O., Khan, M.M., Ansari, S.A., Amal, I., Lee, J. and Cho, M.H. (2014) Enhanced Thermoelectric Performance and Ammonia Sensing Properties of Sulfonated Polyaniline/Graphene Thin Films. Materials Letters, 114, 159162. http://dx.doi.org/10.1016/j.matlet.2013.09.098

[5] Bulakhe, R., Patil, S., Deshmukh, P., Shinde, N. and Lokhande, C. (2013) Fabrication and Performance of Polypyrrole (Ppy)/ $/ \mathrm{TiO}_{2}$ Heterojunction for Room Temperature Operated LPG Sensor. Sensors and Actuators B: Chemical, 181, 417-423. http://dx.doi.org/10.1016/j.snb.2013.01.056

[6] Talwar, V., Singh, O. and Singh, R.C. (2014) ZnO Assisted Polyaniline Nanofibers and Its Application as Ammonia Gas Sensor. Sensors and Actuators B: Chemical, 191, 276-282. http://dx.doi.org/10.1016/j.snb.2013.09.106

[7] He, L., Jia, Y., Meng, F., Li, M. and Liu, J. (2009) Gas Sensors for Ammonia Detection Based on Polyaniline-Coated 
Multi-Wall Carbon Nanotubes. Materials Science and Engineering: B, 163, 76-81. http://dx.doi.org/10.1016/j.mseb.2009.05.009

[8] Abdulla, S., Mathew, T.L. and Pullithadathil, B. (2015) Highly Sensitive, Room Temperature Gas Sensor Based on Polyaniline-Multiwalled Carbon Nanotubes (PANI/MWCNTs) Nanocomposite for Trace-Level Ammonia Detection. Sensors and Actuators B: Chemical. http://dx.doi.org/10.1016/j.snb.2015.08.002

[9] Kar, P. and Choudhury, A. (2013) Carboxylic Acid Functionalized Multi-Walled Carbon Nanotube Doped Polyaniline for Chloroform Sensors. Sensors and Actuators B: Chemical, 183, 25-33. http://dx.doi.org/10.1016/j.snb.2013.03.093

[10] Huang, L., Jiang, P., Wang, D., Luo, Y., Li, M., Lee, H. and Gerhardt, R.A. (2014) A Novel Paper-Based Flexible Ammonia Gas Sensor via Silver and SWNT-PABS Inkjet Printing. Sensors and Actuators B: Chemical, 197, 308-313. http://dx.doi.org/10.1016/j.snb.2014.02.081

[11] Cui, S.M., Pu, H.H., Lu, G.H., Wen, Z.H., Mattson, E.C., Hirschmugl, C., Gajdardziska-Josifovska, M., Weinert, M. and Chen, J.H. (2012) Fast and Selective Room-Temperature Ammonia Sensors Using Silver Nanocrystal-Functionalized Carbon Nanotubes. ACS Applied Materials \& Interfaces, 4, 4898-4904. http://dx.doi.org/10.1021/am301229w

[12] Kondawar, S., Agrawal, S., Nimkar, S., Sharma, H. and Patil, P. (2012) Conductive Polyaniline-Tin Oxide Nanocomposites for Ammonia Sensor. Advanced Material Letters, 3, 393-398.

[13] Kondawar, S.B., Patil, P.T. and Agrawal, S.P. (2014) Chemical Vapour Sensing Properties of Electrospun Nanofibers of Polyaniline/ZnO Nanocomposites. Advanced Material Letters, 5, 389-395.

[14] Jang, W.K., Yun, J., Kim, H.-I. and Lee, Y.-S. (2011) Preparation and Characteristics of Conducting Polymer-Coated Multiwalled Carbon Nanotubes for a Gas Sensor. Carbon Letters, 12, 162-166. http://dx.doi.org/10.5714/CL.2011.12.3.162

[15] Whitby, R.L., Korobeinyk, A., Mikhalovsky, S.V., Fukuda, T. and Maekawa, T. (2011) Morphological Effects of Single-Layer Graphene Oxide in the Formation of Covalently Bonded Polypyrrole Composites Using Intermediate Diisocyanate Chemistry. Journal of Nanoparticle Research, 13, 4829-4837. http://dx.doi.org/10.1007/s11051-011-0459-z

[16] Sirivisoot, S., Pareta, R. and Webster, T.J. (2011) Electrically Controlled Drug Release from Nanostructured Polypyrrole Coated on Titanium. Nanotechnology, 22, Article ID: 085101. http://dx.doi.org/10.1088/0957-4484/22/8/085101

[17] Tiwari, D.C., Atri, P. and Sharma, R. (2015) Sensitive Detection of Ammonia by Reduced Graphene Oxide/Polypyrrole Nanocomposites. Synthetic Metals, 203, 228-234. http://dx.doi.org/10.1016/j.synthmet.2015.02.026

[18] Xiang, C.L., Jiang, D.D., Zou, Y.J., Chu, H.L., Qiu, S.J., Zhang, H.Z., Xu, F., Sun, L.X. and Zheng, L.J. (2015) Ammonia Sensor Based on Polypyrrole-Graphene Nanocomposite Decorated with Titania Nanoparticles. Ceramics International, 41, 6432-6438. http://dx.doi.org/10.1016/j.ceramint.2015.01.081

[19] An, K.H., Jeong, S.Y., Hwang, H.R. and Lee, Y.H. (2004) Enhanced Sensitivity of a Gas Sensor Incorporating Single-Walled Carbon Nanotube-Polypyrrole Nanocomposites. Advanced Materials, 16, 1005-1009. http://dx.doi.org/10.1002/adma.200306176

[20] Huyen, D.N., Tung, N.T., Vinh, T.D. and Thien, N.D. (2012) Synergistic Effects in the Gas Sensitivity of Polypyrrole/Single Wall Carbon Nanotube Composites. Sensors, 12, 7965-7974. http://dx.doi.org/10.3390/s120607965

[21] Montoya, P., Mejía, S., Goncales, V.R., de Torresi, S.I.C. and Calderón, J.A. (2015) Performance Improvement of Macroporous Polypyrrole Sensor for Detection of Ammonia by Incorporation of Magnetite Nanoparticles. Sensors and Actuators B: Chemical, 213, 444-451. http://dx.doi.org/10.1016/j.snb.2015.02.118

[22] Singh, S., Yadav, B., Singh, A. and Dwivedi, P.K. (2012) Synthesis of Nanostructured Iron-Antimonate and Its Application as Liquefied Petroleum Gas Sensor. Advanced Materials Letters, 3, 154-160. http://dx.doi.org/10.5185/amlett.2011.11318

[23] Barkade, S., Pinjari, D., Nakate, U., Singh, A., Gogate, P., Naik, J., Sonawane, S. and Pandit, A. (2013) Ultrasound Assisted Synthesis of Polythiophene/ $\mathrm{SnO}_{2}$ Hybrid Nanolatex Particles for LPG Sensing. Chemical Engineering and Processing: Process Intensification, 74, 115-123. http://dx.doi.org/10.1016/j.cep.2013.09.005

[24] Venkatesan, R. and Cindrella, L. (2015) Semiconducting Composite of Chalcone-Bridged Polythiophene and Titania, Its Ammonia Vapor Sensing Property. Materials Science in Semiconductor Processing, 34, 126-137. http://dx.doi.org/10.1016/j.mssp.2015.02.025

[25] Yun, J., Im, J.S., Kim, H.-I. and Lee, Y.-S. (2012) Effect of Oxyfluorination on Gas Sensing Behavior of Polyaniline-Coated Multi-Walled Carbon Nanotubes. Applied Surface Science, 258, 3462-3468. http://dx.doi.org/10.1016/j.apsusc.2011.11.098

[26] Ngo, C.L., Le, Q.T., Ngo, T.T., Nguyen, D.N. and Vu, M.T. (2013) Surface Modification and Functionalization of Carbon Nanotube with Some Organic Compounds. Advances in Natural Sciences: Nanoscience and Nanotechnology, 4, Article ID: 035017.

[27] Sahoo, N.G., Jung, Y.C., So, H.H. and Cho, J.W. (2007) Polypyrrole Coated Carbon Nanotubes: Synthesis, Characterization, and Enhanced Electrical Properties. Synthetic Metals, 157, 374-379. 
http://dx.doi.org/10.1016/j.synthmet.2007.04.006

[28] Zhang, B., Xu, Y., Zheng, Y., Dai, L., Zhang, M., Yang, J., Chen, Y., Chen, X. and Zhou, J. (2011) A Facile Synthesis of Polypyrrole/Carbon Nanotube Composites with Ultrathin, Uniform and Thickness-Tunable Polypyrrole Shells. Nanoscale Research Letters, 6, 431. http://dx.doi.org/10.1186/1556-276X-6-431

[29] Manivel, P., Kanagaraj, S., Balamurugan, A., Ponpandian, N., Mangalaraj, D. and Viswanathan, C. (2014) Rheological Behavior and Electrical Properties of Polypyrrole/Thermally Reduced Graphene Oxide Nanocomposite. Colloids and Surfaces A: Physicochemical and Engineering Aspects, 441, 614-622. http://dx.doi.org/10.1016/j.colsurfa.2013.10.031

[30] Liu, Y., Wang, H.H., Zhou, J., Bian, L.Y., Zhu, E.W., Hai, J.F., Tang, J. and Tang, W.H. (2013) Graphene/Polypyrrole Intercalating Nanocomposites as Supercapacitors Electrode. Electrochimica Acta, 112, 44-52. http://dx.doi.org/10.1016/i.electacta.2013.08.149

[31] Schnoor, T.I., Smith, G., Eder, D., Koziol, K.K., Burstein, G.T., Windle, A.H. and Schulte, K. (2013) The Production of Aligned MWCNT/Polypyrrole Composite Films. Carbon, 60, 229-235. http://dx.doi.org/10.1016/j.carbon.2013.04.016

[32] Liu, P., Wang, X. and Li, H.D. (2013) Preparation of Carboxylated Carbon Nanotubes/Polypyrrole Composite Hollow Microspheres via Chemical Oxidative Interfacial Polymerization and Their Electrochemical Performance. Synthetic Metals, 181, 72-78. http://dx.doi.org/10.1016/j.synthmet.2013.08.010

[33] Mahore, R.P., Burghate, D.K. and Kondawar, S.B. (2014) Development of Nanocomposites Based on Polypyrrole and Carbon Nanotubes for Supercapacitors. Advanced Material Letters, 5, 400-405.

[34] Sahoo, S., Karthikeyan, G., Nayak, G.C. and Das, C.K. (2011) Electrochemical Characterization of in Situ Polypyrrole Coated Graphene Nanocomposites. Synthetic Metals, 161, 1713-1719. http://dx.doi.org/10.1016/j.synthmet.2011.06.011

[35] Van Hieu, N., Dung, N.Q., Tam, P.D., Trung, T. and Chien, N.D. (2009) Thin Film Polypyrrole/SWCNTs Nanocomposites-Based $\mathrm{NH}_{3}$ Sensor Operated at Room Temperature. Sensors and Actuators B: Chemical, 140, 500-507. http://dx.doi.org/10.1016/j.snb.2009.04.061

[36] Mane, A., Navale, S., Pawar, R., Lee, C. and Patil, V. (2015) Microstructural, Optical and Electrical Transport Properties of $\mathrm{WO}_{3}$ Nanoparticles Coated Polypyrrole Hybrid Nanocomposites. Synthetic Metals, 199, 187-195. http://dx.doi.org/10.1016/j.synthmet.2014.11.031

[37] Wu, T.-M., Chang, H.-L. and Lin, Y.-W. (2009) Synthesis and Characterization of Conductive Polypyrrole/MultiWalled Carbon Nanotubes Composites with Improved Solubility and Conductivity. Composites Science and Technology, 69, 639-644. http://dx.doi.org/10.1016/j.compscitech.2008.12.010

[38] Chen, A., Kamata, K., Nakagawa, M., Iyoda, T., Wang, H. and Li, X. (2005) Formation Process of Silver-Polypyrrole Coaxial Nanocables Synthesized by Redox Reaction between $\mathrm{AgNO}_{3}$ and Pyrrole in the Presence of Poly (Vinylpyrrolidone). The Journal of Physical Chemistry B, 109, 18283-18288. http://dx.doi.org/10.1021/jp053247x

[39] Waghuley, S., Yenorkar, S., Yawale, S. and Yawale, S. (2008) Application of Chemically Synthesized Conducting Polymer-Polypyrrole as a Carbon Dioxide Gas Sensor. Sensors and Actuators B: Chemical, 128, 366-373. http://dx.doi.org/10.1016/j.snb.2007.06.023

[40] Ram, M.K., Yavuz, O. and Aldissi, M. (2005) $\mathrm{NO}_{2}$ Gas Sensing Based on Ordered Ultrathin Films of Conducting Polymer and Its Nanocomposite. Synthetic Metals, 151, 77-84. http://dx.doi.org/10.1016/j.synthmet.2005.03.021

[41] Arab, M., Berger, F., Picaud, F., Ramseyer, C., Glory, J. and Mayne-L’Hermite, M. (2006) Direct Growth of the Multi-Walled Carbon Nanotubes as a Tool to Detect Ammonia at Room Temperature. Chemical Physics Letters, 433, 175181. http://dx.doi.org/10.1016/j.cplett.2006.10.036

[42] Bekyarova, E., Davis, M., Burch, T., Itkis, M., Zhao, B., Sunshine, S. and Haddon, R. (2004) Chemically Functionalized Single-Walled Carbon Nanotubes as Ammonia Sensors. The Journal of Physical Chemistry B, 108, 19717-19720. http://dx.doi.org/10.1021/jp0471857

[43] Yu, Y.J., Ouyang, C., Gao, Y., Si, Z.H., Chen, W., Wang, Z.Q. and Xue, G. (2005) Synthesis and Characterization of Carbon Nanotube/Polypyrrole Core-Shell Nanocomposites via in Situ Inverse Microemulsion. Journal of Polymer Science Part A: Polymer Chemistry, 43, 6105-6115. http://dx.doi.org/10.1002/pola.21114

[44] Zhang, X.T., Zhang, J., Wang, R.M., Zhu, T. and Liu, Z.F. (2004) Surfactant-Directed Polypyrrole/Cnt Nanocables: Synthesis, Characterization, and Enhanced Electrical Properties. ChemPhysChem, 5, 998-1002. http://dx.doi.org/10.1002/cphc.200301217

[45] Chen, Y.-S., Li, Y., Wang, H.-C. and Yang, M.-J. (2007) Gas Sensitivity of a Composite of Multi-Walled Carbon Nanotubes and Polypyrrole Prepared by Vapor Phase Polymerization. Carbon, 45, 357-363. http://dx.doi.org/10.1016/j.carbon.2006.09.011

[46] Lokhande, C., Gondkar, P., Mane, R.S., Shinde, V. and Han, S.-H. (2009) CBD Grown ZnO-Based Gas Sensors and Dye-Sensitized Solar Cells. Journal of Alloys and Compounds, 475, 304-311. 
http://dx.doi.org/10.1016/j.jallcom.2008.07.025

[47] Yan, T., Li, T.X., Wang, R.Z. and Jia, R. (2015) Experimental Investigation on the Ammonia Adsorption and Heat Transfer Characteristics of the Packed Multi-Walled Carbon Nanotubes. Applied Thermal Engineering, 77, 20-29. http://dx.doi.org/10.1016/j.applthermaleng.2014.12.001

[48] Sharma, S., Hussain, S., Singh, S. and Islam, S. (2014) MWCNT-Conducting Polymer Composite Based Ammonia Gas Sensors: A New Approach for Complete Recovery Process. Sensors and Actuators B: Chemical, 194, $213-219$. http://dx.doi.org/10.1016/j.snb.2013.12.050

[49] Kotresh, S., Ravikiran, Y., Kumari, S.V., Prakash, H.R. and Thomas, S. (2015) Polyaniline Niobium Pentoxide Composite as Humidity Sensor at Room Temperature. Advanced Materials Letters, 6, 641-645.

[50] Cho, J.-H., Yu, J.-B., Kim, J.-S., Sohn, S.-O., Lee, D.-D. and Huh, J.-S. (2005) Sensing Behaviors of Polypyrrole Sensor under Humidity Condition. Sensors and Actuators B: Chemical, 108, 389-392. http://dx.doi.org/10.1016/j.snb.2004.12.082

[51] Jung, D., Han, M. and Lee, G.S. (2014) Humidity-Sensing Characteristics of Multi-Walled Carbon Nanotube Sheet. Materials Letters, 122, 281-284. http://dx.doi.org/10.1016/j.matlet.2014.02.049

[52] Navale, S., Mane, A., Chougule, M., Sakhare, R., Nalage, S. and Patil, V. (2014) Highly Selective and Sensitive Room Temperature $\mathrm{NO}_{2}$ Gas Sensor Based on Polypyrrole Thin Films. Synthetic Metals, 189, 94-99. http://dx.doi.org/10.1016/j.synthmet.2014.01.002 